\title{
Social intelligence design in ambient intelligence
}

\author{
A. Nijholt · Oliviero Stock · Toyoaki Nishida
}

Received: 12 December 2008/Accepted: 19 December 2008/Published online: 18 February 2009

(c) The Author(s) 2009. This article is published with open access at Springerlink.com

\section{Introduction}

This Special Issue of AI and Society contains a selection of papers presented at the sixth Social Intelligence Design Workshop held at ITC-irst, Povo (Trento, Italy) in July 2007. Being the sixth in a series means that there is a wellestablished and also a growing research area now. The interest in this research area is growing because, amongst other things, current computing technology allows other than the traditional efficiency-oriented applications associated with computer science and interface technology. For example, in ambient intelligence (AmI) applications we look at sensor-equipped environments and devices (robots, smart furniture, virtual humans and pets) that support their human inhabitants during their everyday activities. These everyday activities also include computer-mediated communication, collaboration and community activities.

As first mentioned by Mark Weiser in his now famous paper 'The Computer for the 21st Century' (Weiser 1991): "The most profound technologies are those that disappear. They weave themselves into the fabric of everyday life until they are indistinguishable from it."

Hence, we talk about computer technology that weaves itself into the fabric of everyday life. The fabric of future

\footnotetext{
A. Nijholt $(\bowtie)$

HMI Group, Department of Computer Science,

University of Twente, Enschede, The Netherlands

e-mail: anijholt@cs.utwente.nl

O. Stock

IRST-Fondazione Bruno Kessler, Povo, Trento, Italy

e-mail: stock@fbk.eu

T. Nishida

Graduate School of Informatics, Kyoto University, Kyoto, Japan

e-mail: nishida@i.kyoto-u.ac.jp
}

everyday life includes what we now see around us: other people, animals, furniture, clothes, walls, and devices that support us and our children in our daily home, recreational, office, and mobile activities. In this fabric we will have intelligent sensors that detect what we are doing, share knowledge amongst them, and interpret what is going on. In addition to this 'invisible' intelligence embedded in the environment we will have human-like robots and also virtual humans displayed in virtual and mixed reality environments that interact with their human partners in human-like ways.

Home and other environments, humanoids, and devices that see, hear, and feel what we are doing will become familiar with us. They will know about our background and history, they will know about our preferences, our moods and emotions, and they will therefore be able to anticipate what we want. Hence, we enter an era of artificial rational and social intelligence and of affective and empathic computing.

Sensor-equipped environments allow implicit and explicit interaction. We have implicit interaction if the environment understands and anticipates our actions and activities. Sensors capture 'awareness' information and provide context-aware feedback or use this awareness information to provide perceptual seamless access to virtual or mixed reality worlds. Anomalies of daily activities can be detected and the environment and its devices may decide to inform or ask the inhabitant about what is going on, it may autonomously take action to repair or recover from a certain situation or it may issue a warning to a monitoring system. Recommender systems may suggest activities or commands based on preferences of inhabitants of smart environments.

We need to design and implement interfaces, whether they are invisible or not. In particular, this design should 
address the issue of 'social and natural interaction' for the human user. That is, we need to look at verbal and nonverbal behaviour of humans when they interact with each other, their children, and their pets. We should understand what roles are played by gaze, head orientation, gestures, posture, and verbal interaction and these roles should also be modelled in order to embed similar capabilities into synthesized environments and humanoids.

\section{Social intelligence design}

The central concern of social intelligence design (SID) is understanding and augmentation of social intelligence that might be attributed to both an individual and a group. We consider social intelligence as the necessary ability for people to relate to understand and interact effectively with others. The particular concern addressed in the SID workshops is how Social Intelligence is mediated through the use of emerging information and communication technologies.

Integrating, understanding, and designing social intelligence was identified in the first workshop held in Matsue, Shimane, Japan, in 2001 (Nishida 2001). This first workshop, SID 2001, was intended to launch this new interdisciplinary study. The dual views of social intelligence, an individual's ability to be able to "manage relationship with other agents and act wisely in a situation governed by an implicit or explicit set of shared rules, based on an ability of monitoring and understanding of other agents' mental state" and an ability of a group of people to manage complexity and learn from experiences as a function of the design of social structure, were identified and equally emphasized.

The second workshop, SID 2003, focused on the theories to enhance the understanding and conceptualization of human cognition and interpersonal interaction to emphasize the practical aspects of SID (Fruchter et al. 2005). The major outcomes of the second workshop include: experimental approach to the design of interactive workspaces, ethnographic studies of the introduction of technologies, the building stories methodologies for studying construction projects, the studies of online communities where mediated communication is a key vehicle for creating and maintaining social contact, building an interactive system that aids human decision and action, an analysis of the dynamism of the virtual community, and analysis of the effect of anonymous communication in online community.

The third workshop, SID 2004 (Nijholt and Nishida 2006), distinguished themes such as (1) Natural interactions-covering theory, modelling and analytical frameworks that have been developed with SID in mind, including situated computation, embodied conversational agents, sociable artefacts, socially intelligent robots, (2) Communities-covering community media, communication patterns in online communities, knowledge-creating, network and anonymous communities, (3) Collaboration Technologies and tools-covering innovations to support interactions within communities, covering a range from knowledge sharing systems, multi-agent systems and interactive systems, and (4) Application Domainsincluding design, workspaces, education, e-commerce, entertainment, digital democracy, digital cities, policy and business.

The major outcomes of this workshop involved the analysis of the effect of employing embodied conversational agents or communicative robots in human-artifact communication, analysis of presence in distributed workspaces, analysis of the effect of long-term use of distributed workspaces, analysis and modelling of meeting, analysis of network search activities, and an effort on compensating digital divide.

The fourth workshop, SID 2005 (Fruchter et al. 2007), added the multi-disciplinary perspective: exploring SID at the intersection of different disciplines, such as, peopleplace process, place-technology interaction, that brings technology, work spaces, social behaviours and process aspects together. The major results involve a theory of improvisational social acts and communication, extending SID issues in extreme emergency and regular meeting room cases, analysis of the weblog community, supporting knowledge capture, sharing, transfer and reuse in collaborative teams.

Both the fifth SID workshop (Miura and Matsumura 2009) and the sixth workshop (SID 2007) emphasized (1) Development, operation, and evaluation of support systems or tools for SID, which includes support systems and tools both for mediated remote interaction and support for faceto-face interaction; (2) Observation and modelling of psychological and behavioural processes with the aim of obtaining computational models of behaviour and interaction; (3) Social intelligence implemented in interfaces, embodied agents, storytelling environments, (serious) gaming and simulation.

\section{Social intelligence design, ambient intelligence, (multi-) agent systems}

Ten updated versions of papers presented at the SID 2007 workshop held in Trento (Italy) have been selected for inclusion in this special issue of AI \& Society. They reflect the various viewpoints mentioned above. For example, in many of the papers various aspects of embedding social intelligence in individual agents and in multiagents systems are discussed. These aspects include social judgments, 
social interaction and social beliefs. A large group of papers also assumes the AmI point of view where we have to deal with disappearing computers and nevertheless we have to interact with computing technology embedded in 'the fabrics of everyday life'. This viewpoint rightly assumes that there is a convergence of AmI (i.e., ubiquitous computing + social and intelligent interfaces) and the developments towards an 'Internet of Things, People, and Services'. Here we can find selected SID 2007 papers that address matters, such as capturing and interpreting humanhumanoid (virtual humans, robotic devices) interaction, human-human (multi-party) interaction, and human-environment interaction.

As mentioned, SID 2007 took place at ITC-irst, Povo (Trento). We gratefully acknowledge help from ITC-irst in organizing this workshop. During SID 2007 invited talks were given on 'Awareness Systems' (Panos Markopoulos, University of Eindhoven), 'Ontologies and Organisations' (Nicola Guarino, ISTC-CNR, Trento), and on 'Monitoring the Social Attitude of Users in Persuasion Dialogues' (Fiorella de Rosis, University of Bari). We are grateful to the advisory and program committee and all others that helped in organizing this workshop.
Open Access This article is distributed under the terms of the Creative Commons Attribution Noncommercial License which permits any noncommercial use, distribution, and reproduction in any medium, provided the original author(s) and source are credited.

\section{References}

Fruchter R, Nishida T, Rosenberg D (2005) Understanding mediated communication: the social intelligence design (SID) approach. AI Soc 19(1):1-7

Fruchter R, Nishida T, Rosenberg D (2007) Mediated communication in action: a social intelligence design approach. AI Soc 22(2):93-100

Miura A, Matsumura N (2009) Social intelligence design: a junction between engineering and social sciences. AI Soc 23(2):139-145

Nijholt A, Nishida T (2006) Social intelligence design for mediated communication. AI Soc 20(2):119-124

Nishida T (2001) Social intelligence design-an overview. In: Terano T, Nishida T, Namatame A, Ohsawa Y, Tsumoto S, Washio T (eds) Exploring new frontiers on artificial intelligence-selected papers from the first international workshops of Japanese Society of Artificial Intelligence, LNAI 2253. Springer Heidelberg, pp 3-10

Weiser M (1991) The computer for the twenty-first century. Scientific American, September, pp 94-110 